\title{
Different Effects of the Toxoplasma on Rats: A Review
}

\author{
Review Article
}

Volume 3 Issue 1- 2022

\begin{abstract}
Author Details
Maziar Naderi', Shaghayegh Akhoundi khezrabad², Mehrsa Mennati ${ }^{3}$, Nafiseh Sami ${ }^{4}$, Arash Faradjzadeh

Mevaloo $^{5}$, Afrooz Farhadi ${ }^{6}$, Mohammad Yavari ${ }^{7 *}$

${ }^{1}$ Medical Student, Tehran Medical Sciences Branch, Islamic Azad University, Tehran, Iran

${ }^{2}$ Medical Student, Tehran Medical Sciences Branch, Islamic Azad University, Tehran, Iran

${ }^{3}$ Medical Student, Tehran Medical Sciences Branch, Islamic Azad University, Tehran, Iran

${ }^{4}$ Student Research Committee, Tehran Medical Sciences, Islamic Azad University, Tehran, Iran

${ }^{5}$ Medical Student, Tehran Medical Sciences Branch, Islamic Azad University, Tehran Iran

${ }^{6}$ Medical student, Ali Ibn Abi Talib Medical university, Islamic Azad university, Yazd, Iran

${ }^{7}$ Bachelor of Science in Nursing, Islamic Azad University Tehran Branch, Tehran, Iran

*Corresponding author

Mohammad Yavari, Bachelor of Science in Nursing, Islamic Azad University Tehran Branch, Tehran, Iran

Article History

Received: January 20, 2022 Accepted: January 21, 2022 Published: February 02, 2022
\end{abstract}

\begin{abstract}
Toxoplasma gondii is a forced intracellular parasite dominated by cats. In this article, by examining various tests and serological tests on different groups of wild mice (rats), we examine the effects of this parasite on different organs of the body, including the digestive system, heart, nervous system, genitals, hormones and also the immune system. Tests performed on adult and able-to-mate mice indicate the parasite's ability to change reproduce functions in males and the hormonal factors that affect it, females and their fetuses, and the sexual and asexual behaviors of mice. In some parts of this article, the effects of drugs such as nitric oxide acetylcholinesterase and glucocorticoids on this parasite are discussed.
\end{abstract}

Keywords: Toxoplasma rats; Effect toxoplasma; Toxoplasma gondii rats

\section{Introduction}

Toxoplasma gondii is an enteric coccidian parasite of the cat. As an apicomplexan protist, $\mathrm{T}$. gondii is an intra- cellular parasite that completes its life cycle within the small intestine of the cat, which is the definitive host, where the parasite undergoes sexual reproduction to pro-duce oocysts. These unsporulated oocysts, which measure 11$13 \mu \mathrm{m}$ in diameter, are excreted in the infected cat's feces. Following development in the environment, termed sporulation, the sporulated oocysts that are ingested by an intermediate host release sporozoites, and these infect the cells of the intestine and lymph nodes where they transform into a rapidly dividing asexual stage termed a tachyzoite. The tachyzoites disseminate to other parts of the body, and their rapid multiplication and associated destruction of host cells result in acute toxoplasmosis, which is characterized by mild to severe clinical signs depending on the organ system affected and the immune status of the host. Following this acute stage, the formation of tissue cysts containing a slow reproducing bradyzoite stage occurs. These tissue cysts, which typically form in the brain, liver and muscle, can persist for the life of the intermediate host. Upon ingestion by the cat, bradyzoites are released from tissue cysts and undergo asexual reproduction within the epithelium of the cat small intestine, followed by sexual reproduction and the production of oocysts. However, if other intermediate hosts ingest the tissue cysts, the acute stage of the life cycle, characterized by tachyzoite replication and dissemination, is initiated. If infection occurs during pregnancy, tachyzoites can be transmitted vertically to the fetus. They may be associated with severe clinical outcomes depending on the timing of the infection and the host species involved.

\section{a. Impact on NO}

Plasma NO levels increase during toxoplasmosis infection [1].

\section{b. Impact on diabetes}

In the diabetic group, increased brain parasites and IgM titers were also reported. Therefore, hyperglycemia can increase the burden of brain parasites and immunoglobulin titers [2].

Also, detection of active presence of Toxoplasma gondii in different organs of rat body after experimental infection with RH strain shows that Organs such as the kidneys are not a good place for Toxoplasma to live, but the parasite can be present in organs such as the spleen and liver for a short time, but in the brain and muscles for a long time.

\section{c. Serology and immune system}

Clinically, there was no significant difference between IG and CG, but the following were observed in measuring SE, IG and CG. AST enzyme increased during the first 8 hours of PI and at 40-32 and 48-56 PI, but 
changes in the level of this enzyme in the PI weeks between IG and CG were not significantly different. ALT enzyme increased during 8 hours of PI as well as 56-48 hours, but the difference in changes of this enzyme in PI weeks between IG and CG was not significant. ALK/P enzyme increased PI during 24-40 hours and 64-48 hours. Changes in the level of this enzyme during PI weeks did not show a significant difference between IG and CG. CPK enzyme increased PI during 40-40 and 48-56 hours, but in PI weeks, the difference between this enzyme between IG and CG was not significant. The changes in LDH enzyme were quite similar to CPK enzyme. ACP enzyme increased during PI 16-48 hours but its changes between IG and CG were not significantly different [3].

Also, 100 mice were used to study the serum prevalence of $\mathrm{Tg}$ in $\mathrm{Wr}$, which were classified according to gender (male and female), weight and habitat (urban and rural). The age of mice was classified into weight category and serum prevalence was assessed by $\mathrm{Mm}$ test. $\mathrm{Mm}$ test showed that $45 \%$ of male mice and $55 \%$ of female mice tested positive for $\mathrm{Tg}$, which showed there is no large difference between the two gender. In terms of habitat, SR showed that $61.8 \%$ of positive tests were related to rural mice and $34.6 \%$ were related to urban mice, which is a significant difference indicating the impact of habitat. The Sr results showed that $36.3 \%$ of the positive results were related to young mice and $61.5 \%$ to adults, which shows a significant difference in the rate of Tg infection [4].

In another experiment, three groups were formed, the first and second groups were infected with Tg brady zoite, the second group was also IS and the third group was CG. They were evaluated weekly by MAT with methanol (AC) or formalin (HS) and IFAT. IFAT could not distinguish between acute and chronic phases. MAT-AC only detected antibodies in the acute phase. But MAT-HS detects antibodies in both phases [5].

But in another study, we analyzed the effects of Ep on immunological responses by referring to the Cytokine level of Tg-infected mice, which is propolis day by day until the end of the experiment, day 28 . From the second week until the end of the experiment, Propolis had the highest Tg antibody titer compared to CG. Cytokine levels in the serum of Propolis-treated mice were steadily increased compared to CG. Serum cytokine levels of mice after Tg infection showed that TnfAlpha, IL-1beta, IL-6 were increased compared to CG or the treated group [6].

The ability to scan 131I-Pyrimethamine for lesions of Tg infection was evaluated. The presence of toxoplasmosis was confirmed 60 days after implantation. Primetamine was radioactive with I131. i-Pyrimethamine was injected intravenously into the tail vein of CG and IG mice. The target areas (ROIs) were drawn on the organs (thyroid, stomach, liver, bladder, and soft tissues) to calculate the ratio of radio-trackers in infected individuals to healthy individuals. The mean radiofrequency ratio in infected / control rats in the liver and diaphragm was more than 1 in 45 minutes, which remained up to 24 hours. In conclusion, 131 I-Pyrimethamine may be a useful agent for the diagnosis of toxoplasmosis, particularly in the liver and diaphragm, which requires further preclinical validation before it can be used in clinical applications [7].

In a study of the distribution of $\mathrm{Tg}$ in female $\mathrm{Wr}$ tissues that were immunized by or with It. One week after confirmation of pregnancy, Tg was inoculated with brady zoite, oocyte and tachysoite. 48 pregnant mice were grouped according to the form of $\mathrm{Tg}$ they are inoculated with. Two groups, one as control group and the other as immunized group. After delivery, milk samples were collected for 3 weeks and then mice were killed and tissue and milk samples were examined by qPCR. Toxoplasma's immunization was found to reduce $\mathrm{Pl}$ in muscle samples of mice inoculated with bradiolite and oocytes. Parasite DNA was found in milk during Lp in both immunized and non-immunized mice. No changes in $\mathrm{pl}$ were found by immunization [8].
One study also looked at the distribution of Tg in the tissues of female and infant mice. 48 pregnant mice were grouped with different forms of Tg according to immunization or not and inoculation and also one group was considered as CG. After delivery, the mice were sacrificed and their tissues were removed by PCR to investigate Tg DNA and qPCR to determine Pl. Immunization of mice against Tg reduced $\mathrm{Pl}$ in most organs. It also had a positive effect on fetal birth rate and weight [9].

For another test related to the effect on the immune system, 10 male mice were divided into two groups: CG and IG. IGs were injected intraperitoneally with TG tachyzoite. TLR4mRN was determined in the brain after 10 weeks. TGR4 gene and IL-1 beta in Pbs were significantly increased in IGs compared to CGs. IL-4 levels were also elevated, but not significantly. TLR4 may be involved in inflammatory reactions in the brain of mice damaged by $\mathrm{Tg}$ due to mesenteric infection [10].

Also, 88 male mice are divided into two groups, IG and CG. IG mice become infected with $\mathrm{Tg}$ tachyzoite intraperitoneally. One day before infection and day $3,6,9,12 \ldots .30 \mathrm{Pi} 4$ mice from each group were killed for serum and testis. Serum IFN-gamma levels increased rapidly and peaked on day $6 \mathrm{Pi}$ and then decreased rapidly. IL-4 increased slowly, reaching a maximum on day $12 \mathrm{Pi}$ and then decreasing. On day $6 \mathrm{Pi}$, testicular sperm duct cells are disrupted. The number of primary and secondary spermatocytes decreased dramatically. Bax in infected mice and in spermatogenic cells, especially spermatocytes, increased on day 3 pi and reached a maximum on day 6 and returned to normal by day 15 . Bcl-2 did not change much in infected mice. Tg causes severe damage to host spermatogenic cells [11]

One study examined the activity of E-NTPDase and E-ADA in the lymphocytes of mice infected with Tg in vitro. Twenty-four male Wr were divided into two groups infected with $\mathrm{Tg}$ inoculation and the non-infected group. Sampling was performed on days 5 and 10 after infection. Enzyme assays showed an increase in ATP hydrolase on day 10, and E-ADA activity was observed in both periods. Based on the increased activity of E-NTPDase and E-ADA in lymphocytes, they may be involved in the anti-inflammatory response, including the modulatory response, preventing further tissue damage due to $\mathrm{Tg}$ contamination [12].

In another serology-related study, $48 \mathrm{SD}$ mice were infected with $\mathrm{Tg}$ tachyzoite and divided into eight groups. Six mice were injected as salinity control and 4 mice remained as normal control. Peripheral blood was collected and measured by ELISA on days $1,3,7,14,28,35,42,60$ levels of IFN-gamma, TFN-alpha, IL-4 was measured. IFN-gamma and IL-4 levels increased in mice tested on day 7 Pi. TFN-alpha levels increased on day 28 and CD8 T lymphocytes were significantly lower than control mice that recovered on day 28 . No specific change was observed in CD4 T lymphocytes. TFN-alpha, IFN-gamma, IL-4, and CD8 levels of T lymphocytes can be affected by Tg infection if CD4 remains unchanged [13].

Cs of honey was fed orally as a natural food to the tested mice and compared to the control group, we saw an increase in the level of antibodies in the serum of mice infected with Cs of honey. Cs of Honey increases serum antibodies as well as increases cytokine levels in Tg-infected mice [14].

None of the clinical signs of toxoplasmosis were observed in IR. Some TG1000 mice exhibit $\mathrm{Hu}$ protein transport to the nucleus, which reduces CI and visualizes cell body limitations. The neurological changes seen in this experimental model on IR were not sufficient to stimulate CS toxoplasmosis, such as diarrhea. The mechanisms involved in these effects should be investigated further. Although CV occurs in neurons that are at risk, the presence of these vacuoles is not necessarily related to neuronal death. In addition, $\mathrm{HuC} / \mathrm{D}+$ neurons, 
nNOS - and nNOS + with abnormal aspects were often observed in the TG5000 group [15].

According to the experiments, the sera of all mice in the control group were negative for TI, but all mice infected with TT showed infection. The ratio of body weight to testis in IG did not change significantly compared to CG on days 10-70 PI. $(P<0.05)$ Sperm parameters

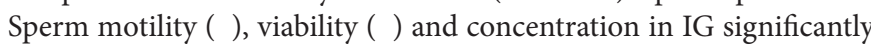
decreased on days 10-70 PI, 10-60PI and 20-60PI compared to CG ( $P$ $<0.05)-0.01$ ) While sperm abnormalities (\%) in IG increased on days 30-50PI $(P<0.05-0.01$ but on days 60-70 PI returned to normal [16].

TL and Th in EG were significantly lower than CG. Th / Ts showed significant differences between groups. Levels of $\mathrm{Fe} 2+, \mathrm{Cu} 2+$ were significantly lower in EG IR. They had higher levels of Mg2 + than CG. $\mathrm{Zn} 2+$ and $\mathrm{Ca} 2+$ levels were similar in both groups [17]

\section{Genetics}

In one study, 286 wild mice were collected and their DNA was obtained from their brain and heart tissue to generate the SAG1 gene from these hosts. These mice were divided into 4 groups and positive samples were examined by PCR. It was found that $24 \%$ of the tissue of these wild mice was infected with this parasite. More than $55.8 \%$ of tissues belonged to Rr, $17.6 \%$ to tissues belonged to Rn, $14.7 \%$ to tissues belonged to $\mathrm{Mm}$ and $11.7 \%$ to Ro. Infection was 50 mice for genotype III and 18 mice for genotype II. The results showed that the type of mice involved in the spread of this infection SAG1 is also an important molecule in detecting Tg infection [18].

Also, the brains of 40 mice were removed and their DNA was obtained. In this study, a repetitive sequence of the $\mathrm{Tg}$ genome was used for identification with a specific primer. 7 strains of positive samples were identified by PCR. Of the 40 samples, 20 samples (50\%) were positive for the $529-\mathrm{Bp}$ band. Samples 21 and 28 had $95 \%$ and $92 \%$ similarity to the RH strain sequence. The most similar sequence was with the RH strain [19].

\section{d. Nervous system}

In one study, 37 groups of Wr were exposed to 2,000 cysts of $15 \mathrm{Tg}$ species. After 2 months, 323 of 411 mice, or $78.6 \%$, were infected with Tg cysts. 2000 cysts were required to infect about $90 \%$ of mice, with lower doses infecting about $60 \%$. Bc was formed in only 146 of 411 mice. The number of cysts formed ranged from 10 to 1,000 (sometimes $2,000)$. As the dose of Tg cysts increases, the number of infected mice and cysts formed in the brain increases [20].

In another experiment, 12 pregnant SD mice were divided into two groups: IG and CG. Mice in IG were inoculated intraperitoneally with RH strain tachyosite from TG. After 5 days, blood samples were taken from Cv. On days 9, 10, and 11, two mice in each group were killed and RT-PCR was used in their amniotic fluid to look for Toxoplasma $\mathrm{B} 1$ gene to prove Tg. Both Bs and RT-PCR results indicated that mice and their embryos were infected with Tg. Ifs for MAP2 and GFAP showed that the neuronal dissociation percentage was $15.15 \%$ in CG and $8.73 \%$ in IG. With a statistical difference, the percentage of dissociation of strocytes was $53.35 \%$. In both groups, NCAM protein was found in fetal neural tissue. Tg in the first days of pregnancy may prevent the growth, differentiation and migration of nerve stem cells in neurons [21].

In an experiment with 6 different species of TO, WR was used to infect 6 groups 4-24. Two months later, the mice were killed and their brains were screened for TC. Freshly weaned cats with a negative DA test were used to obtain TO. Cats received carcasses and brains of mice with chronic Toxoplasma infection. Two months after Toxoplasma inoculation was seen in BC form or improved by bioassay in 113 of $138(82 \%)$ mice. BC was observed in the brain 68 of 138 (49\%). Even feeding mice with 10,000 oocytes had no effect on the growth of cysts. The overall infection rate in mice fed Toxoplasma was $82 \%$. The results showed that KSU and M7741 toxoplasma were significantly more contagious than Hopa-Hopa and KSU was the most contagious. The species of mice also had an effect on TI. Toxoplasma improved in the brains of all FRs but not in LRs. Also, the infectivity of TO is much higher compared to TC [22].

\section{e. The effect of glucocorticoids on the incidence of Toxoplasma}

Glucocorticoids (such as methylprednisolone) can inhibit the production of nitric oxide, its constituent mRNA, and related proteins in macrophages. Increased production of Toxoplasma gondii cysts in the brain was another complication of glucocorticoid therapy. These changes were observed 12 and 24 hours after injection [23].

\section{f. The effect of Toxoplasma on pregnancy}

Wh6 infection, before or during pregnancy, can cause abnormalities in rat pregnancy. Also, the highest urea level and significant decrease in Arg-1 expression was seen in the group with chronic infection during pregnancy. Macrophage production of nitric oxide was higher in the group with chronic pre-pregnancy infection compared to the control groups [24].

Also, female rats naturally avoid infected male rats, such as Toxoplasmosis, but according to the present study, the Toxoplasma gondii parasite modifies the male attraction and signal between the sexes in a way that benefits the parasite. This ultimately gives the male rat a better chance of finding a placenta and transmitting the infection [25].

\section{g. Impact on fertility and reproductive system}

In a study related to the reproductive system, the effect of Toxoplasma gondii on the reproductive system of male rats is investigated. From 10 days after infection for 70 days, the desired variables were measured and the results showed that motility, viability and sperm concentration decreased but returned to normal within 70 days. Except for sperm motility. Sperm abnormalities were also reported. Other observations suggest that the infection can cause unstable damage to the male reproductive system, including changes in ST, ITT, SLDH, intratesticular LDH, and intra-seminal vesicles fructose and coagulation levels. Decreased ST and ITT were seen only on day 10, increased SLDH only on day 10 , decreased intra-testicular LDH only on day 30 , and finally decreased fructose on days 10 to 50 . Structurally, decreased spermatozoa and impaired spermatogenesis were seen on days 30-50, but eventually repair was reported [26].

Studies have also shown that infection with Toxoplasma gondii increases the expression of genes that facilitate testosterone production, and therefore, testosterone increases in this infection. This hormone increases the sexual attraction of male rats and alters the animal's fear of cats and its smell so that the parasite completes its life cycle [27].

As a result of the infection, on days 30 and 40 , an increase in sperm abnormalities, up to about $30 \%$ of sperm were detectable. There was no significant difference between the two groups in body weight and mean testicular weight. Although tissue cysts have been found in parts of the brain and pituitary gland; But no damage was found. As a result, toxoplasmosis can exhibit significant effects on key factors in the male reproductive system of rats that are very effective in determining fertility [28].

\section{h. Effect on hormones}

This was not significantly different from the control group and rats without ovaries. On the other hand, measuring the amount of estrogen and progesterone in the bloodstream showed that there was no difference in the amount of steroid hormones in the blood of rats 
that were gonadally healthy. These cases prove that the mechanism of reducing cat odor sensitivity in female rats is not related to ovarian health or ovarian steroids [29].

\section{i. Impact on the reproductive system}

ST and ITT decreased significantly on day 10 PI, S-LDH increased significantly on day $10 \mathrm{PI}$, IT-LDH decreased significantly on day 30 PI, and fructose concentration in SVCG on day 10, PI 20, 30, 40 and 50 were significantly reduced [30].

According to the results, IAG sperm motility and FSH and LH levels were significantly reduced compared to CG. The difference in hormone levels between the two IAG groups was negligible. We saw significant differences between IAG and CG in toxoplasmosis-infected blood cells and purulent cells and WBCs (increase in IAG). But after 12 weeks, PC had the greatest effect, such as congestion, $\mathrm{SH}$, and bleeding in the blood vessels between the tubules by reducing the size of these tubules and witnessing necrosis and loss of most epithelial layers of epididym and reducing the size of the epididymal tubes. We also saw infection after 6 weeks, and the epididymal cavity was empty of sperm [31].

Studies have shown that the effect of onion juice on sperm parameters and testosterone levels in rats infected with $\mathrm{Tg}$ in vitro at $40 \mathrm{Wr}$ in 4 groups was investigated. The first group was infected with CG and the second group was infected with Tg tachyzoite and received $1 \mathrm{cc}$ of onion juice daily. Group 3 received only onion juice and group 4 received only Tg tachyzoite. After 30 days of $\mathrm{Pi}$, blood was collected from rats to measure testosterone levels. Serum levels of testosterone and Sc were significantly reduced in Tg-infected mice. Compared to CG, testicular weight was reduced in infected mice. Tg has been shown to affect serum testosterone levels, and onion juice can prevent these destructive effects [32].

$20 \mathrm{Wr}$ were divided into IG and CG groups and IGs were infected with $\mathrm{Tg}$ tachyzoite intraperitoneally and nothing was injected into CGs. After 30 days, their blood was tested for testosterone, AP, and Mda levels, and the epididymal tissue in these mice was examined for analysis, and it was found that testosterone and AP in IGs compared with CGs increased dramatically and no significant change in Mda was observed in either group. Epididymal weight was significantly reduced in IGs compared to CGs. In IGs, brown APs were observed in the epididymal tissue. These indicate that TG infection affects testosterone and AP levels and also has destructive effects on the epididymis in infected mice [33].

In another study, mice were divided into two groups, female and male, each of which was $42 \mathrm{Rn}$ mice in the weight range of 250 to 300 grams. Half of the mice were infected intraperitoneally with $\mathrm{Tg}$ tachyzoite. The infected and healthy groups were divided into 3 subgroups and treated with DMSO, sulphadiazine, pyrimethamine. At the end of the treatment period, healthy and infected male mice in each subgroup mated with healthy female mice and also healthy and infected female mice in each subgroup mated with healthy male mice. Female mice were killed on day 15 of gestation and the embryos were examined. The size of healthy female fetuses mated with non-infected males treated with DMSO was significantly larger than that of fetuses mating with healthy females infected with DMSO-treated males. This conclusion was also true for healthy and infected males treated with pyrimenthamine and suiphadiazine. Finally, histological changes in the embryos were examined and no particular changes were observed in the tissues of the kidneys, liver, and lungs of the fetuses of both infected and noninfected males and females who were treated with any drug. Regarding the physical characteristics, we saw a decrease in the size and weight of the fetuses and an increase in reabsorption and premature death in the Tg-infected group, which can be attributed to the endocrine effects of Tg infection. In infected mice, the hypothalamic nuclei of SO and pv were shown to be deformed. IL- $1 n$ levels also increased in toxoplasmosis. And further disrupts the secretion of pituitary and gonadal hormones, which reduces fertility [34].

Sperm parameters, hormone levels (testosterone, FSH and LH) and histomorphometric analyzes are performed every 10 days in male Wr infected Tg toads until the 80th day. Sperm parameters such as motility, viability and normal sperm such as LH levels were significantly reduced in Tg-infected mice. There was no significant decrease in testosterone and FSH levels. The number of Lcs decreased significantly on the 20th day. On day 60 , a significant reduction in SC was shown. Weight loss was seen on days 20 and 60 , but testicular weight increased.Tg infection can reduce fertility parameters but does not cause sterilization in mice. The parasite can temporarily disrupt the reproductive system of male mice [35].

\section{j. Impact on the heart}

30 male Wr were divided into 3 groups: CG and IG2. The IG1 group was inoculated with $0.3 \mathrm{ml}$ of Tg tachyzoite and the IG2 group was inoculated with $0.6 \mathrm{ml}$ of water, and the CG was given water daily. Atrophy and necrosis were observed in their heart tissue in groups infected with $\mathrm{Tg}$ [36].

\section{Epidemiology}

The aim of this study was to investigate the prevalence of T.gondii parasite in brown rats (Rattus norvegicus) in Grenada between April and December 2005. Heart and brain tissue samples as well as serum of 238 rats (119 males and 199 females) that were randomly collected from the city were studied. After examining the presence of antibodies against this parasite by Modified Agglutination Test (MAT), this parasite was confirmed in only two rats $(0.8 \%)$ and in only one sample of heart and brain tissue, the parasite was found. The parasite found in heart and brain tissue was inoculated into two groups of 5 mice. All were asymptomatic, although cysts were found in the brains of mice. It can be concluded that in this geographical area, mice do not play a significant role in the life cycle of Toxoplasma gondii [37].

In a study, between November 2009 and January 2010, the serum of 217 rats collected from Rattus norvegicus and Rattus flavipectus from southern China were examined. Modified agglutination test (MAT) showed only 7 positive cases, all of which were female. Although only $3.2 \%$ of the study group in this study were carriers of the parasite, but considering the large number of rats in the city, their role in the life cycle of this parasite is significant [38].

A study of 127 wild rats (Rattus rattus) including 73 female and 54 male rats from different parts of Ahvaz city in the period of February 2008 to January 2011 showed the serum outbreak of Toxoplasma gondii by Immunochromatography (ICA) for antibody testing. Serum levels were evaluated against this parasite. The results showed that $24.41 \%$ of rats tested positive for antibodies. Also, these rodents were classified according to the time and place of collection and in summer and in the east of Ahvaz, the prevalence was slightly higher. In general, these rats in the city of Ahvaz are epidemiologically a risk factor for this infection [39].

In this study, to investigate the prevalence of Toxoplasma gondii, 63 blood samples including 43 samples from rats collected from public resorts in southern Brazil, 20 samples from Curitiba Zoo and 20 laboratory-bred rats over a period of time. From July 2013 to January 2014, the results were similar to those of the previous study by JP Dubey et al., With a prevalence of $0.3-8 \%$ [40].

In this study, the prevalence of Toxoplasma gondii in East China and in synanthropic rodents was investigated. The final results showed that 
this parasite has a high prevalence and this report can be an important issue in maintaining and improving the environment and cats (and animals). This study was performed as a genetic and molecular study [41].

\section{k. Impact on the digestive system}

Acute infection with Toxoplasma gondii in rats can cause deformities in the wall of the duodenum and its epithelial cells [42].

Chronic parasitic infection confirmed by observation of brain cysts showed structural changes in the jejunum indicating a decrease in submucosal neurons with atrophy of villi, caverns, and mucosal and submucosal layers. Also, the thickness of anthrocytes decreased and their length increased [43].

Also, the effect of this infection on jejunal cells was measured. After examination, a decrease was seen in neutral mucin-producing (PAS + ) and sulfamocin-producing goblet cells; Meanwhile, sialomycinproducing cells remained. In addition, the number of VIP-IR submucosal neurons decreased and atrophy and fluorescence density were reported in these cells. In this study, clinical manifestations of toxoplasmosis such as weight loss also occurred [44].

In another study, $16.20 \%$ of submucosal layer neurons and $22.87 \%$ of sulfomucin-producing goblet cells were destroyed, but VIP-IR neurons increased by about $27 \%$, followed by an increase in VIP factor, which has anti-inflammatory and Is anti-apoptotic, was observed. Also, a significant increase in intraepithelial lymphocytes, an increase in the depth of colon crypts and the thickness of the mucosal layer were observed [45]

In another study, an increase in the expression of ICAM-1 and serotonin (especially 12 and 24 hours after receiving the infectious agent), an increase in the number of mast cells per square meter, a decrease in the space occupied by collagen I was observed. Also, in the study group, after 24 hours, a decrease in the amount of space in the mesenteric ganglia was recorded and a decrease in the thickness of the submucosal layer was observed [46].

In general, the infection causes inflammation of the intestine and diarrhea (without changes in the git and fecal output) as well as the possibility of motor dysfunction in the intestine. 12 hours after infection of male mice with $\mathrm{Tg}$ oocytes, hypertrophy of the colon muscles was observed. Lack of myenteric and cholinergic neurons was observed in the proximal colon. Also, lack of cholinergic neurons in the distal colon was reported. CC prolongs the course of infection in the middle and distal colon, which slows CMC [47].

In another study, the effects of 30- and 90-day Toxoplasmosis infection on myenteric jejunum neurons in 15 rats were investigated. Neuronal atrophy was seen in the 30 -day group, while the 90 -day group was more prone to hypertrophy [48].

In one study, 10 male mice were divided into two groups (5 control mice and 5 experimental mice) and one was given saline solution and the other solution containing 104 parasitic tachyzoites, based on observations of Sgc in the gastric gland area Showed a 27.56\% decrease in the population density of myenteric neurons. ; If Lgc in the same part of the stomach showed a $25.25 \%$ decrease in myenteric neurons this significant decrease in Sgc may be due to the direct and indirect effects of infection due to the greater vulnerability of neurons [49].

Subsequently, further studies were performed on the status of myenteric neurons in the study. 8 mice were divided into 2 control and experimental groups. The experimental group was inoculated with $\mathrm{Tg}$ oocytes (genotype II) orally. In both organs, the end of the ileum and the lower colon, we did not have any neuronal loss, and at the end of the ileum, the neurons became hypertrophic if no morphological changes were seen in the lower colon [50].
In another study, 80 mice were divided into four groups including experimental (acute and chronic) and control (acute and chronic). Two experimental groups were inoculated with $\mathrm{Tg}$ tachyzoite (genotype III) orally. The acute group was killed 24 hours after inoculation and the chronic group was killed 30 days later. The population densities of myenteric neurons and cell bodies in the nuclear and cytoplasm regions were analyzed. Both acute and chronic infections did not destroy neurons in the myenteric neural network of the duodenum, but reduced the level of nucleus and cytoplasm in acute infection and caused neuronal hypertrophy in chronic infection [51].

The results of this study showed that $\mathrm{Tg}$ is able to reduce the number and area of nitrifying myenteric neurons in rats. In ENS, nitrogen neurons are produced and Nitric Oxide (NO) is used as an inhibitory neurotransmitter in response to parasitic infections, including those produced by Tg. Quantitative and morphometric analysis of these neurons was performed in the myenteric network. There was a numerical decrease in neurons per square millimeter in both the jejunum and the distal colon. The remaining nitrogen neurons also atrophied in the cell body and nucleus, reducing the cytoplasm. Thus, Tg infection causes neuronal changes in the small and large intestines of mice in the short term [52].

\section{Impact on behavior}

Previous studies have shown that rats infected with Toxoplasmosis infection show less internal perception and fear than felines compared to healthy rats, and conversely, healthy groups are attracted to feline odors. One study looked at possible differences in rats' reactions to wild cats (Acinonyx jubatus) such as cheetahs (puma) and domestic cats (Felis silvestris catus). The results confirmed previous studies and also showed that rats were more attracted to the smell of domestic cats and in wild animals, no difference was reported between cheetah and puma [53].

It should be noted that the main invasion of the parasite was in the middle regions of the brain and limbic, which can act as a natural mechanism of anxiety [54].

Rats instinctively feel disgusted and dangerous when they see cats, but studies show that Toxoplasma gondii parasites can affect areas of the rat's brain and cause a lethal attraction to the cat [55].

One study found that Toxoplasma gondii infection increases the expression of genes that facilitate testosterone production, and therefore, testosterone increases in this infection. This hormone increases the sexual attraction of male rats and changes the animal's fear of cats and its smell so that the parasite completes its life cycle [56].

In another study, it was further confirmed that Toxoplasmosis infection in male rats may make it more attractive and, as a result, increase the likelihood of its selection by female rats; Although naturally, female rats are absorbed by healthy rats. Also, rats' internal fears and perceptions of cats and their smell are altered and reduced to increase the likelihood of bioparasites. These two behaviors can be due to reactions involving testosterone that have been studied in studies [57].

In another study, it was said that these changes were not due to the olfactory system but to neural activity in the limbic areas. When rats were exposed to cat urine and odor, neural activity in VMHdm, MEApd and amygdala increased [58].

One study found that Toxoplasmosis infection in rats could increase its tendency to make sudden decisions, reduce dopamine levels, and reduce the spinal density of neurons in the nucleus accumbens core. The results show that these dopaminergic changes affect the behavior 
and decision type of rats. Also, as a result of this infection, the rat's distance from cats (deer) is delayed. In addition, no change in rat sensitivity to reward was reported [59].

In general, infected rats have opposite tendencies and their fear and aversion to cats have disappeared, they also do not avoid light and in general have become more risky and more inclined than the control group to search and explore cases. New in the environment showed. However, by examining the estrus cycle, it was observed that the behaviors are affected by this period. In addition, an increase in progesterone levels was recorded in infected rats and it can be concluded that the behaviors are affected by this hormonal change [60].

In addition to the previous cases, no behavioral changes related to anxiety and depression were observed in infected rats. It should be noted that the rate of defecation and time spent in the center of the maze was significantly higher in healthy rats [61].

\section{Impact on leptin}

Twenty male Square-Dawley rats in two groups, one control and the other with Toxoplasma gondii parasite, were examined and tested for 4 weeks, and finally, blood samples were taken to check plasma leptin levels due to infection. Based on the observations, no significant changes in rat weight were reported, but plasma leptin levels were significantly higher in infected rats [62].

\section{m. Transfer by milk}

In this study, the possibility of transmission of Toxoplasma gondii through the milk of female rats was investigated. Immunological tests on infected rat milk, including PCR, IFAT and MAT, confirmed the presence of the parasite in chronic and acute infections. IFAT test also showed parasite transmission to the fetus [63].

\section{n. Association of acetylcholinesterase with Toxoplasma}

Acetylcholinesterase can play an important role in the primary and rapid immune response to Toxoplasma gondii [64].

\section{Conclusion}

The obvious information of this article is that the changes resulting from this parasite are aimed at continuing its life cycle and will have very severe and sometimes irreversible effects on the digestive, cardiac, reproductive, immune, central nervous system and pregnancy. . It is noteworthy that the habitat and type of mice have a significant impact on the clinical manifestations of this parasite. No definitive cure has been found for this parasite.

\section{References}

1. Baltaci AK, Mogulkoc R, Turkoz Y, Bediz CS, Ozugurlu F (2004) The effect of pinealectomy and zinc deficiency on nitric oxide levels in rats with induced Toxoplasma gondii infection. Swiss medical weekly 134(23-24): 359-363.

2. Hassanain M, El-Fadaly H, Hassanain N (2014) Toxoplasma gondii parasite load elevation in diabetic rats as latent opportunistic character. Annals of Tropical Medicine and Public Health 7(2): 110.

3. Alili Sanandajkhah L, Dalimi A (2009) Alteration in some serum enzyme levels of rats during experimental infection with Toxoplasma gondii. Pathobiology Research 12(2): 29-35.

4. Hosseini SA, Abediankenari S, Amouei A, Sarvi S, Sharif M, et al. (2021) Seroprevalence of Toxoplasma gondii in Wild Rats (Rattus rattus) in Northern Iran. Vet Med Int 2021: 6655696.

5. Silva RC, Silva AV, Langoni H (2007) Serological differentiation between acute and chronic stages in experimental toxoplasma infection of normal and immunosupressed rats (Rattus norvegicus). In International Congress in Animal hygiene 13: 885-888.
6. Hegazi AG, Al Guthami FM, Al Gethami AF, Barakat AM (2017) Egyptian propolis 12: influence of Propolis on Cytokines of Toxoplasma gondii Infected Rats. Int J Curr Microbiol App Sci 6(5): 202-211.

7. Inceboz T, Yurt Lambrecht F, Surucu E, Yilmaz O, Yavasoglu A, et al. (2013) Preparation of 131I-Pyrimethamine and evaluation for scintigraphy of experimentally Toxoplasma gondii-infected rats. J Drug Target 21(2): 175-179.

8. Camossi LG, Fornazari F, Richini Pereira VB, da Silva RC, Cardia DF, et al. (2015) Immunization of Wistar female rats with 255-Gy-irradiated Toxoplasma gondii: Tissue parasitic load and lactogenic quantification. Exp Parasitol 154: 163-169.

9. Camossi LG, Fornazari F, Richini Pereira VB, da Silva RC, Cardia DF, et al. (2014) Immunization of Wistar female rats with 255-Gy-irradiated Toxoplasma gondii: preventing parasite load and maternofoetal transmission. Exp Parasitol 145:157-163.

10. Zhou YH, Wang SS, Yang J, Tao JP, Xu YL, et al. (2012) Expression of Tolllike receptor 4 in brain tissue of chronic Toxoplasma gondii infection rats and its effect on brain injury. Zhongguo Xue Xi Chong Bing Fang Zhi Za Zhi 24(1): 58-61.

11. Yang R (2011) Effect of Toxoplasma gondii infection on cytokines and spermatogenic cells in rats. Zhongguo Ji Sheng Chong Xue Yu Ji Sheng Chong Bing Za Zhi 29(4): 274-278.

12. Tonin AA, Da Silva AS, Ruchel JB, Rezer JF, Camillo G, et al. (2013) E-NTPDase and E-ADA activities in lymphocytes associated with the immune response of rats experimentally infected with Toxoplasma gondii. Exp Parasitol 135(2): 325-330.

13. Wang CL, Zhou YH, Liu JH (2006) Changes of peripheral blood T lymphocytes, IFN-gamma, TNF-alpha and IL-4 in rats infected by Toxoplasma gondii. Zhongguo Ji Sheng Chong Xue Yu Ji Sheng Chong Bing Za Zhi 24(2): 122-124.

14. Hegazi AG, Al Guthami FM, Al Gethami AF, El Fadaly HA (2017) Beneficial effects of capparis spinosa honey on the immune response of rats infected with toxoplasma gundii. J Pharmacopuncture 20(2): 112118.

15. Tironi LM, Beraldi EJ, Borges SC, Massocato CL, Vieira SL, et al. (2018) Toxoplasmic Infection-induced Injury in the Ileal Myenteric Plexus in Rats Depends on the Dose of Toxoplasma gondii Oocysts. Journal of Morphological Sciences 35(01): 80-86.

16. Abdoli A, Dalimi A, Movahedin M (2012) Impaired reproductive function of male rats infected with Toxoplasma gondii. Andrologia 44 Suppl 1: 679-867.

17. Geng ZH, Fang YQ, Liu L, Shi Y, Li SH (2001) Determination of T lymphocytes and trace elements in spleen from rats infected with Toxoplasma gondii. Zhongguo Ji Sheng Chong Xue Yu Ji Sheng Chong Bing Za Zhi 19(6): 357-359.

18. Bahadori ES, Sadraei J, Dalimi A, Namroodi S, Pirestani M (2018) Phylogenetic Analysis of Toxoplasma gondii Type II and Type III by PCRRFLP Plus Sequencing on Wild-Rats of Golestan Forest, Iran. J Vet Sci Technol 9: 3.

19. Rashidi S, Sadraei J, Fruzandeh MM, Pirestani M (2012) Isolation and molecular characterization of Toxoplasma gondii strains from rats in Tehran. Jundishapur Journal of Microbiology 5(4): 537-541.

20. Freyre A, Falcon J, Correa O, Mendez J, Gonzalez M, et al. (2001) Residual infection of 15 Toxoplasma strains in the brain of rats fed cysts. Parasitol Res 87(11): 915-918.

21. Sun XN, Liu ZJ, Guan ZY, Liang RW, Zhang HY, et al. (2012) Effect of Toxoplasma gondii infection on the embryonic neural stem cells in rats. Zhongguo Ji Sheng Chong Xue Yu Ji Sheng Chong Bing Za Zhi 30(4): 253-257.

22. Freyre A, Falcon J, Correa O, Mendez J, Gonzalez M, et al. (2003) Cyst burden in the brains of Wistar rats fed Toxoplasma oocysts. Parasitol Res 89(5): 342-344.

23. Wang T, Gao JM, Yi SQ, Geng GQ, Gao XJ, et al. (2014) Toxoplasma 
gondii infection in the peritoneal macrophages of rats treated with glucocorticoids. Parasitol Res 113(1): 351-358.

24. Kong L, Zhang Q, Chao J, Wen H, Zhang Y, et al. (2015) Polarization of macrophages induced by Toxoplasma gondii and its impact on abnormal pregnancy in rats. Acta Trop 143: 1-7.

25. Dass SA, Vasudevan A, Dutta D, Soh LJ, Sapolsky RM, et al. (2011) Protozoan parasite Toxoplasma gondii manipulates mate choice in rats by enhancing attractiveness of males. PloS one 6(11): e27229.

26. Abdoli A, Dalimi A, Movahedin M (2012) Impaired reproductive function of male rats infected with Toxoplasma gondii. Andrologia 44 Suppl 1: 679-687.

27. Lim A, Kumar V, Hari Dass SA, Vyas A (2013) Toxoplasma gondii infection enhances testicular steroidogenesis in rats. Mol Ecol 22(1): 102-110.

28. Terpsidis KI, Papazahariadou MG, Taitzoglou IA, Papaioannou NG Georgiadis MP, et al. (2009) Toxoplasma gondii: reproductive parameters in experimentally infected male rats. Exp Parasitol 121(3): 238-241.

29. Abdulai Saiku S, Vyas A (2017) Loss of predator aversion in female rats after Toxoplasma gondii infection is not dependent on ovarian steroids. Brain Behav Immun 65: 95-98.

30. Abdoli A, Dalimi A, Movahedin M (2010) Andrology: P-3: Changes In Biochemical Parameters Of Reproductive Function In Male Rats Infected With Toxoplasma Gondii. International journal of fertility and sterility 4(1): 52-53.

31. Chabuk HA (2019) Some Physiological and Histological Changes in the Male Reproductive System of Rats (Rattus Rattus) Experimentally Infected with Toxoplasma Gondii. Biochem Cell Arch 19(2): 4393-4398.

32. Khaki A, Ghadamkheir E, Ouladsahebmadarek E, Hagighi A, Ahmadi S (2013) Recovery of sertoli cells by Allium cepa in Toxoplasma gondii infected rats. Journal of Clinical Medicine and Research 5(1): 1-4.

33. Afshari F, Imani AM, Asl SN, Farhang HH, Ghasempour K, et al. (2013) Evaluation of testosterone and alkaline phosphatase activity changes in epidydimis of Toxoplasma gondii infected rats. International Journal of Women's Health and Reproduction Sciences 1(2): 64-71.

34. Al Ghezy ZS, Al Abady FA, Al Snafi AE (2016) Effect of Toxoplasma gondii infection in male and female rats on fetal characteristics. European Journal of Biomedical and Pharmaceutical Sciences 3(5): 692-698.

35. Taherimoghaddam M, Bahmanzadeh M, Tapak L, Maghsood AH, Fallah M, et al. (2021) Effects of Toxoplasma gondii on Sperm Parameters and Histomorphometry of Testis in Experimentally Infected Rats. Archives of Clinical Infectious Diseases 16(2).

36. Najjare Aghdam H, Khaki A, Garedaghi Y (2020) Evaluation of Tissue Changes in the Hearts of Rats Infected with Toxoplasma Gondi. Int J Med Parasitol Epidemiol Sci 1(2): 39.

37. Dubey JP, Bhaiyat MI, Macpherson CN, De Allie C, Chikweto A, et al. (2006) Prevalence of Toxoplasma gondii in rats (Rattus norvegicus) in Grenada, West Indies. J Parasitol 92(5): 1107-1108.

38. Yin CC, He Y, Zhou DH, Yan C, He XH, et al. (2010) Seroprevalence of Toxoplasma gondii in rats in southern China. J Parasitol 96(6): 12331234

39. Mosallanejad B, Avizeh R, RAZI JM, Hamidinejat H (2012) Seroprevalence of Toxoplasma gondii among wild rats (Rattus rattus) in Ahvaz District, Southwestern Iran. Jundishapur Journal of Microbiology 5(1): 332-335

40. Pellizzaro M, Conrado FD, Martins CM, Joaquim SF, Ferreira F, et al. (2017) Serosurvey of Leptospira spp. and Toxoplasma gondii in rats captured from two zoos in Southern Brazil. Rev Soc Bras Med Trop 50(6): 857-860.

41. Yan C, Liang LJ, Zhang BB, Lou ZL, Zhang HF, et al. (2014) Prevalence and genotyping of Toxoplasma gondii in naturally infected synanthropic rats (Rattus norvegicus) and mice (Mus musculus) in eastern China. Parasit Vectors 7(1): 1-5.
42. Pavanelli MF (2017) Comparacao da patogenicidade das assemblages A e B de Giardia duodenalis sobre o intestino delgado de camundongos Swiss.

43. Vicentino Vieira SL, Gois MB, Trevizan AR, de Lima LL, Leatte EP, et al. (2017) Toxoplasma gondii infection causes structural changes in the jejunum of rats infected with different inoculum doses. Life Sci 191: 141149.

44. Sant'Ana DM, Gois MB, Zanoni JN, da Silva AV, da Silva CJ, et al. (2012) Intraepithelial lymphocytes, goblet cells and VIP囚IR submucosal neurons of jejunum rats infected with Toxoplasma gondii. Int J Exp Pathol 93(4): 279-86

45. Gois MB, Hermes Uliana C, Zago MCB, Zanoni JN, da Silva AV, et al. (2016) Chronic infection with Toxoplasma gondii induces death of submucosal enteric neurons and damage in the colonic mucosa of rats. Exp Parasitol 164: 56-63.

46. Pastre MJ, Casagrande L, Gois MB, Pereira Severi LS, Miqueloto CA, et al. (2019) Toxoplasma gondii causes increased ICAM-1 and serotonin expression in the jejunum of rats $12 \mathrm{~h}$ after infection. Biomed Pharmacother 114: 108797.

47. Machado CCA, Watanabe PdS, Mendes JDAdL, Pupim ACE, Ortigoza SM, et al. (2021) Toxoplasma gondii infection impairs the colonic motility of rats due to loss of myenteric neurons. Neurogastroenterology \& Motility 33(1): e13967.

48. Hermes Uliana C, Pereira Severi LS, Luerdes RB, Franco CLM, Da Silva AV, et al. (2011) Chronic infection with Toxoplasma gondii causes myenteric neuroplasticity of the jejunum in rats. Auton Neurosci 160(12): 3-8.

49. Alves MS, Silva AVd, Bianchi LRdO, Araujo EJdA, Sant'Ana DdMG (2011) Toxoplasma gondii induces death of gastric myenteric neurons in rats. Int J Morphol 29(1): 293-298.

50. Sugauara EYY, Sant'Ana DdMG, da Silva AV, de Souza EA, de Almeida Araujo EJ (2009) Hypertrophy of the neurons in the ileum of rats infected with cysts of Toxoplasma gondii (genotype II). Acta Scientiarum Biological Sciences 31(2): 195-201.

51. Papazian Cabanas RM, Araujo EJ, Silva AVd, Sant’Ana DM (2012) Myenteric neuronal plasticity induced by Toxoplasma gondii (genotype III) on the duodenum of rats. An Acad Bras Cienc 84(3): 737-746.

52. Sant'Ana DdMG, Gois MB, Hermes Uliana C, Pereira Severi LS, Baptista EM, et al. (2017) Acute infection with an avirulent strain of Toxoplasma gondii causes decreasing and atrophy of nitrergic myenteric neurons of rats. Acta Histochem 119(4): 423-427.

53. Kaushik M, Knowles S, Webster J (2014) What makes a feline fatal in Toxoplasma gondii's fatal feline attraction? Infected rats choose wild cats. Integr Comp Biol 54(2): 118-128.

54. Gonzalez LE, Rojnik B, Urrea F, Urdaneta H, Petrosino P, et al. (2007) Toxoplasma gondii infection lower anxiety as measured in the plus-maze and social interaction tests in rats: a behavioral analysis. Behav Brain Res 177(1): 70-79.

55. Berdoy M, Webster JP, Macdonald DW (2000) Fatal attraction in rats infected with Toxoplasma gondii. Proc Biol Sci 267(1452): 1591-1594.

56. Lim A, Kumar V, Hari Dass SA, Vyas A (2013) Toxoplasma gondii infection enhances testicular steroidogenesis in rats Mol Ecol 22(1): 102110.

57. Vyas A (2013) Parasite-augmented mate choice and reduction in innate fear in rats infected by Toxoplasma gondiiJ Exp Biol 216(1): 120-126.

58. House PK, Vyas A, Sapolsky R (2011) Predator cat odors activate sexual arousal pathways in brains of Toxoplasma gondii infected rats. PLoS One 6(8): e23277.

59. Tan D, Soh LJT, Lim LW, Daniel TCW, Zhang X, et al. (2015) Infection of male rats with Toxoplasma gondii results in enhanced delay aversion and neural changes in the nucleus accumbens core. Proc Biol Sci 282(1808): 20150042 . 
60. Golcu D, Gebre RZ, Sapolsky RM (2014) Toxoplasma gondii influences aversive behaviors of female rats in an estrus cycle dependent manner. Physiol Behav 135: 98-103.

61. Parvin Z, Iraj MD, Minoo S, Fatemeh K (2016) Effects of Toxoplasma gondii infection on anxiety, depression and ghrelin level in male rats. J Parasit Dis 40(3): 688-693.

62. Baltaci A, Mogulkoc R (2012) Plasma leptin levels in rats with induced Toxoplasma gondii infection. Bratisl Lek Listy 113(2): 67-69.
63. Costa V, Langoni H (2010) Detection of Toxoplasma gondii in the milk of experimentally infected Wistar female rats. J Venom Anim Toxins incl Trop Dis 16(2): 368-374.

64. Tonin AA, da Silva AS, Thorstenberg ML, Castilhos LG, França RT, et al. (2013) Influence of Toxoplasma gondii acute infection on cholinesterase activities of Wistar rats. Korean J Parasitol 51(4): 421-426. 